\title{
Seven distinct dietary patterns identified among pregnant Finnish women - associations with nutrient intake and sociodemographic factors
}

\author{
Tuula Arkkola ${ }^{1, *}$, Ulla Uusitalo², Carina Kronberg-Kippilä², Satu Männistö², \\ Mikko Virtanen ${ }^{2}$, Michael G Kenward ${ }^{3}$, Riitta Veijola ${ }^{1}$, Mikael Knip ${ }^{4,5}$, \\ Marja-Leena Ovaskainen ${ }^{2}$ and Suvi M Virtanen $2,6,7$ \\ 'Department of Paediatrics, PO Box 5000, 90014 University of Oulu, Oulu, Finland: ${ }^{2}$ Department of Health \\ Promotion and Chronic Disease Prevention, National Public Health Institute, Helsinki, Finland: ${ }^{3}$ Department of \\ Epidemiology and Population Health, Medical Statistics Unit, London School of Hygiene \& Tropical Medicine, \\ London, UK: ${ }^{4}$ Hospital for Children and Adolescents, University of Helsinki, Helsinki, Finland: ${ }^{5}$ Department of \\ Paediatrics, Tampere University Hospital, Tampere, Finland: ${ }^{6}$ Tampere School of Public Health, University of \\ Tampere, Tampere, Finland: ${ }^{7}$ Research Unit, Tampere University Hospital, Tampere, Finland
}

Submitted 24 October 2006: Accepted 14 March 2007: First published online 5 July 2007

\begin{abstract}
Objectives: To identify and describe dietary patterns in a cohort of pregnant women and investigate whether the dietary patterns are associated with dietary intake and sociodemographic factors.

Design: Mothers entering the Finnish Type 1 Diabetes Prediction and Prevention (DIPP) Nutrition Study in 1997-2002 were retrospectively asked to complete a food-frequency questionnaire concerning their diet during pregnancy. Principal components analysis was used to identify dietary patterns.

Setting: Finland.

Subjects: Subjects were 3730 women with a newborn infant carrying increased genetic susceptibility to type 1 diabetes mellitus.

Results: Seven factors were identified and named. Energy intake correlated positively with 'Healthy', 'Fast food', 'Traditional bread', 'Traditional meat' and 'Coffee' patterns and inversely with the 'Alcohol and butter' pattern. Intake of dietary fibre correlated positively with 'Healthy', 'Traditional bread' and 'Low-fat foods' patterns and inversely with the 'Alcohol and butter' pattern. The seven dietary patterns seemed to account for relatively large proportions of the variance in energy and nutrient intakes except for the intake of vitamin D, vitamin C, carotenoids and calcium. Maternal age and higher level of education were associated with higher scores on 'Healthy', 'Low-fat foods' and 'Alcohol and butter' patterns.

Conclusion: Principal components analysis produced seven dietary patterns which may be useful for further research concerning maternal diet and health outcomes among both mothers and their offspring.
\end{abstract}

Proper nutrition during pregnancy is considered important both for maternal health and foetal growth and development, and hence is addressed by dietary recommendations. An appropriate diet also helps the mother to recover from delivery and supports successful breastfeeding. The traditional way to assess the diet is to examine energy and nutrient intakes or the consumption of certain food items. Dietary pattern analysis is an approach that aims to describe the whole diet in combination. The use of dietary patterns might help to capture some of the complexity of diet that is often lost in nutrient- based analyses ${ }^{1}$, and provide additional information in exploring the relationship between nutrition and health. All foods contribute to nutritional status and it is not the presence or absence of a single food but the appropriate selection of foods in suitable quantities and combinations that is important to health ${ }^{2}$.

Maternal food and nutrient intake during pregnancy has been investigated, but as far as we know only two studies have used dietary pattern analysis ${ }^{3,4}$. The first was performed among Mexican American mothers and reported seven maternal eating patterns ${ }^{3}$. The second was 
a longitudinal study that found two stable dietary patterns from preconception to postpartum in a small cohort $(n=80)$ of Spanish women ${ }^{4}$.

Dietary patterns identified by exploratory factor analysis are reported to account for relatively large proportions of the variance in energy and macronutrient intakes in middle-aged women and men $^{5}$, and to relate to many sociodemographic and lifestyle factors both in women and men ${ }^{4-10}$. There is evidence from earlier studies that older, highly educated and non-smoking pregnant women eat more healthily than others ${ }^{11-15}$

The aim of the present study was to identify and describe dietary patterns in a cohort of pregnant Finnish women. We also examined whether the dietary pattern scores vary by energy and nutrient intakes or sociodemographic factors.

\section{Subjects and methods}

\section{Subject sample}

This analysis represents part of the Nutrition Study within the Finnish Type 1 Diabetes Prediction and Prevention Study (DIPP), which aims to evaluate the effects of both childhood diet and maternal nutrition during pregnancy and lactation on the development of $\beta$-cell autoimmunity and type 1 diabetes mellitus in the offspring. All families with newborn infants carrying increased HLA (human leucocyte antigen)-conferred susceptibility to type 1 diabetes (genotype HLA DQB1*02/*0302 or HLA $D Q B 1{ }^{*} 0302 / x ; x \neq *^{*} 02,{ }^{*} 0301$ or $\left.{ }^{*} 0602\right)$ in the Oulu and Tampere University Hospital regions were invited to participate. The present analysis included mothers who gave birth between October 1997 and December 2002 $(n=5362)$. Complete nutrition information was received from 3730 mothers (70\% of those invited), who formed the final study population. Sociodemographic data were collected using a structured questionnaire. Those women who did not provide complete nutritional information were less educated and had more children than those who provided nutritional information. Age and smoking during pregnancy did not differ between these two groups. The mean age of the mothers was 30 years, varying between 16 and 47 years. Selected sociodemographic factors are presented in Table 1.

\section{Data collection and processing}

Diet during pregnancy was assessed by a food-frequency questionnaire (FFQ) comprising a list of 181 food items that was validated by Erkkola et al. ${ }^{16}$. The FFQ assessed the use of foods or food groups and the consumption frequency (number of times per day, week or month) as common serving sizes. The questionnaire was specifically designed to reflect Finnish food consumption habits. Mothers were asked to answer questions concerning their
Table 1 Characteristics of 3730 pregnant Finnish women

\begin{tabular}{lrr}
\hline Variable & $n$ & $\%$ \\
\hline Age at delivery (years) & & \\
$<25$ & 723 & 19 \\
$25-29$ & 1277 & 34 \\
$30-34$ & 1103 & 30 \\
$\geq 35$ & 628 & 17 \\
Basic education & 1675 & 45 \\
No high school degree & 1845 & 49 \\
High school degree & 211 & 6 \\
Missing data & & \\
Smoking during pregnancy & 3214 & 86 \\
No & 380 & 10 \\
Yes & 137 & 4 \\
Missing data & & \\
Area & 2196 & 59 \\
Tampere & 1535 & 41 \\
Oulu & & \\
Number of earlier deliveries & 1668 & 45 \\
0 & 1170 & 31 \\
1 & 826 & 22 \\
2 or more & 67 & 2 \\
Missing data & & \\
\hline
\end{tabular}

diet during the month preceding the maternity leave in Finland, i.e. the eighth month of pregnancy. A notice concerning the period of interest was repeated on each page of the questionnaire. Mothers received the questionnaire after delivery and it was returned and checked by a study nurse at the infant's 3-month visit to the study centre. The food consumption data were entered into a dietary database using a software program of the National Public Health Institute, Helsinki, Finland. In-house software with the Fineli national food composition database ${ }^{17}$ was used to calculate daily nutrient intakes. The selected frequency category for each food item in the FFQ was converted to a daily intake. The detailed content of the FFQ and data processing have been described elsewhere $^{16}$

\section{Statistical metbods}

The 181 food items were aggregated into 52 separate food groups (Table 2). The grouping scheme was based on culinary use and nutrient profiles. Principal components analysis with varimax rotation was used to identify patterns among the food groups. The factor model is driven by the idea that correlated variables belong together, and they should be recognised as distinct from groups of variables with which they are not correlated. A plot of eigenvalues (i.e. the Scree test) indicated a break between the seventh and eighth factor which could be used as a separate criterion to the solution of seven factors that were retained for further analyses. After varimax rotation of the factors, food groups with absolute factor loading $\leq-0.2$ or $\geq 0.2$ were considered as significantly contributing to a pattern. Factor scores were calculated for each person in each pattern in terms of how closely they fit the pattern. Factor scores were computed by weighting 
Table 2 Food groupings used in the dietary pattern analysis

\begin{tabular}{|c|c|}
\hline Food or food group & Food items included in group \\
\hline Leafy vegetables & Lettuce \\
\hline Cabbage & Red and white cabbage, cauliflower, kohlrabi, sauerkraut \\
\hline Vegetables & Tomato, cucumber, sweet pepper, onion, garlic, corn, avocado, sprouts \\
\hline Fish & Fish, canned fish, smoked fish \\
\hline Vegetarian dishes & Vegetable soup, risotto, vegetarian patty \\
\hline Legumes and mushrooms & Beans, lentils, green peas, mushrooms \\
\hline Roots & Carrot, vegetable mix, red beet, rutabaga \\
\hline Berries & Strawberry, blackcurrant, blueberry, lingonberry, gloudberry, berry soup \\
\hline Salad dressing & Vegetable oil dressing, low-fat dressing, mayonnaise \\
\hline Poultry & Poultry \\
\hline Fruits & $\begin{array}{l}\text { Orange, apple, banana, pear, peach, grapefruit, plum, pineapple, water melon, kiwi fruit, } \\
\text { fruit salad, dried fruit }\end{array}$ \\
\hline Rice and pasta & Rice, pasta \\
\hline Egg & Boiled eggs, fried eggs \\
\hline Sweets & Sweets \\
\hline Fast food & Pizza, hamburger, deep-fried meat pasty \\
\hline Snacks & Crisps, salted nuts, popcorn \\
\hline Chocolate & Chocolate, chocolate sauce, hot chocolate \\
\hline Fried potatoes & Fried potatoes, French fries, potato casserole \\
\hline Soft drinks & Carbonated beverages \\
\hline Cream & Cream in coffee, whipped cream, ice cream \\
\hline Fruit juices & Orange juice, apple juice, other fruit juice \\
\hline White bread & White bread, white crisp roll \\
\hline Processed vegetables & Vegetable juices, ketchup, pickled vegetables \\
\hline Light soft drinks & Low-energy carbonated beverages \\
\hline Savoury & Carelian pastry, cream crackers, pancakes \\
\hline Low-fat pastry & Low-fat cakes, traditional bunny \\
\hline Whole-grain bread & Whole-grain soft bread, rye bread, crispbread \\
\hline High-fat pastry & High-fat cakes, cream cakes, cookies \\
\hline High-fat cheese & High-fat cheese, special cheese \\
\hline Sugar and jam & Sugar in coffee, jam, sugar, honey \\
\hline Berry juices & Berry juices \\
\hline Meat & Steaks, stews \\
\hline Nuts and seeds & Nuts, seeds \\
\hline Breakfast cereals & Breakfast cereals, muesli, porridge \\
\hline Meat dishes & Meat dishes including potato, rice or pasta \\
\hline Sausage & Sausage dishes \\
\hline Potatoes & Boiled potato, baked potato, mashed potato \\
\hline Processed meat & Cold cuts, bacon, canned meat, smoked meat \\
\hline Organ meat & Liver, blood \\
\hline Spread 40-60\% & Butter-vegetable oil $40-60 \%$, soft margarine $40-60 \%$ \\
\hline Low-fat cheese & Low-fat cheese, fat-modified cheese \\
\hline High-fat milk & Whole milk, $1.9 \%$ milk \\
\hline Low-fat milk & Skimmed milk, $1 \%$ milk \\
\hline Butter & Butter, butter-vegetable oil $80 \%$ \\
\hline Low-fat sour milk & Fat-free sour milk, low-fat yoghurt \\
\hline High-fat sour milk & Sour milk, whole yoghurt \\
\hline Coffee & Coffee \\
\hline Milk in coffee & Milk in coffee \\
\hline Tea & Tea, herbal teas \\
\hline Beer & Beer, long drink \\
\hline Wine, liquor & White wine, red wine, dessert wine, spirits \\
\hline Soft margarine 80 & Soft margarine $80 \%$ \\
\hline
\end{tabular}

each factor loading by the factor's eigenvalue, multiplying these weights with the subject's corresponding food group intake, and summing these products. Factor scores were used to rank individuals.

Pearson's correlation coefficients were calculated between dietary patterns and energy and nutrient intakes. Multiple linear regression analysis was used to test how age, educational level, smoking during pregnancy, living area and the number of earlier deliveries explained the variance in pattern scores. All statistical analyses were performed using SPSS for Windows v. 14.0 (SPSS Inc.).

\section{Results}

\section{Dietary patterns}

Seven factors were identified to describe the dietary patterns of the pregnant Finnish women (Table 3). Collectively these factors explained $29.5 \%$ of the variability within the sample. Food items with loadings of $\geq 0.2$ on a factor were considered to have a strong association with that factor. Negative loading $(\leq-0.2)$ represents an inverse association between the food item and the factor. The seven factors were named according to the food item 
Table 3 Factor loadings $\leq-0.2$ or $\geq 0.2$ of different food items in the seven dietary factors identified using principal components analysis with varimax rotation

\begin{tabular}{|c|c|c|c|c|c|c|c|}
\hline Food item & Healthy & Fast foods & Traditional bread & Traditional meat & Low-fat foods & Coffee & Alcohol and butter \\
\hline$\%$ of variability & 7.6 & 6.1 & 3.9 & 3.2 & 3.1 & 2.9 & 2.7 \\
\hline Leafy vegetables & 0.577 & & & & & & \\
\hline Cabbage & 0.537 & & & & & & \\
\hline Vegetables & 0.523 & & & & & & \\
\hline Fish & 0.519 & & & & & & \\
\hline Vegetarian dishes & 0.461 & & & & & & \\
\hline Legumes and mushrooms & 0.447 & & & & & & \\
\hline Roots & 0.421 & & & & & & \\
\hline Berries & 0.408 & & 0.204 & & & & \\
\hline Salad dressing & 0.398 & & & & & & 0.302 \\
\hline Poultry & 0.367 & & & & & & \\
\hline Fruits & 0.361 & & & & & & -0.276 \\
\hline Rice and pasta & 0.301 & & & & & & \\
\hline Egg & 0.300 & 0.212 & & & & & \\
\hline Sweets & & 0.595 & & & & & \\
\hline Fast food & & 0.575 & & & & & \\
\hline Snacks & & 0.537 & & & & & \\
\hline Chocolate & & 0.509 & & & & & \\
\hline Fried potatoes & & 0.493 & & & & & \\
\hline Soft drinks & & 0.444 & & & & & 0.225 \\
\hline Cream & 0.232 & 0.370 & & & & & \\
\hline Fruit juices & & 0.346 & & & & & -0.214 \\
\hline White bread & & 0.330 & & & & & \\
\hline Processed vegetables & 0.206 & 0.321 & & 0.226 & & & \\
\hline Light soft drinks & & 0.307 & & & 0.205 & & \\
\hline Savoury & & 0.251 & 0.214 & & & & \\
\hline Low-fat pastry & & & 0.525 & & & 0.246 & \\
\hline Whole-grain bread & & -0.252 & 0.502 & & 0.285 & & \\
\hline High-fat pastry & & 0.420 & 0.451 & & & & \\
\hline High-fat cheese & & & 0.359 & & & & \\
\hline Sugar and jam & & & 0.358 & & & & \\
\hline Berry juices & & & 0.332 & & & & \\
\hline Meat & & & & 0.553 & & & \\
\hline Nuts and seeds & 0.320 & & 0.207 & -0.539 & & & \\
\hline Breakfast cereals & 0.389 & & 0.288 & -0.470 & & & -0.239 \\
\hline Meat dishes & 0.257 & & 0.205 & 0.442 & & & \\
\hline Sausage & & 0.222 & & 0.405 & & 0.202 & \\
\hline Potatoes & & -0.252 & 0.310 & 0.365 & & & \\
\hline Processed meat & & 0.225 & 0.225 & 0.336 & 0.321 & & \\
\hline Organ meat & & & & 0.280 & & & \\
\hline Spread $40-60 \%$ & & & & & 0.577 & & \\
\hline Low-fat cheese & 0.283 & & & & 0.485 & & \\
\hline High-fat milk & & & & & -0.461 & 0.281 & -0.203 \\
\hline Low-fat milk & & & & & 0.450 & & \\
\hline Butter & & & 0.256 & & -0.354 & & 0.327 \\
\hline Low-fat sour milk & 0.280 & & & & 0.282 & & \\
\hline High-fat sour milk & & & 0.204 & & -0.250 & & \\
\hline Coffee & & & & & & 0.803 & \\
\hline Milk in coffee & & & & & & 0.639 & \\
\hline Tea & & & 0.387 & & & -0.463 & \\
\hline Beer & & & & & & & 0.493 \\
\hline Wine, liquor & & & & & & & 0.486 \\
\hline Soft margarine 80 & & & & 0.307 & -0.215 & & -0.371 \\
\hline
\end{tabular}

loadings as 'Healthy', 'Fast foods', 'Traditional bread', 'Traditional meat', 'Low-fat foods', 'Coffee' and 'Alcohol and butter' (Table 3).

\section{Dietary intake and sociodemographic factors}

Pattern scores were differently associated with energy and nutrient intakes (Table 4). Energy intake correlated positively with 'Healthy', 'Fast food', 'Traditional bread' and 'Traditional meat' patterns and inversely with the 'Alcohol and butter' pattern. Intake of dietary fibre correlated positively with 'Healthy', 'Traditional bread' and 'Low-fat foods' patterns and inversely with the 'Alcohol and butter' pattern. The seven dietary patterns seemed to account for rather large proportions (over 50\%) of the variance in energy and nutrient intakes except for the intake of vitamin D, vitamin C, carotenoids and calcium (Table 4).

Dietary pattern scores were differently associated with age, educational level, smoking during pregnancy, living 
Table 4 Pearson correlation coefficients between dietary pattern score and energy and energy-adjusted nutrient intakes, and proportion of explained variance in energy and nutrient intakes in pregnant Finnish women $(n=3730)$

\begin{tabular}{|c|c|c|c|c|c|c|c|c|}
\hline \multirow[b]{2}{*}{ Nutrient } & \multicolumn{7}{|c|}{ Dietary pattern } & \multirow[b]{2}{*}{$\begin{array}{c}\text { Proportion of } \\
\text { variance explained }\end{array}$} \\
\hline & Healthy & $\begin{array}{l}\text { Fast } \\
\text { foods }\end{array}$ & $\begin{array}{l}\text { Traditional } \\
\text { bread }\end{array}$ & $\begin{array}{l}\text { Traditional } \\
\text { meat }\end{array}$ & $\begin{array}{l}\text { Low-fat } \\
\text { foods }\end{array}$ & Coffee & $\begin{array}{l}\text { Alcohol } \\
\text { and butter }\end{array}$ & \\
\hline Energy (kJ) & $0.40^{\star \star \star}$ & $0.52^{\star \star *}$ & $0.59^{\star \star \star}$ & $0.24^{\star \star \star}$ & 0.01 & $0.09^{\star \star \star}$ & $-0.12^{\star \star \star}$ & 86.5 \\
\hline Protein $(\mathrm{g})$ & $0.50^{* \star *}$ & $0.33^{\star \star *}$ & $0.46^{\star \star *}$ & $0.27^{\star \star \star}$ & $0.19^{\star \star \star}$ & $0.11^{\star \star *}$ & $-0.15^{\star \star \star}$ & 71.5 \\
\hline Carbohydrates (g) & $0.38^{\star \star \star}$ & $0.49^{\star \star \star}$ & $0.59^{\star \star \star}$ & $0.12^{\star \star \star}$ & $0.06^{\star \star \star}$ & $0.07^{\star \star \star}$ & $-0.15^{\star \star \star}$ & 77.3 \\
\hline Sucrose $(\mathrm{g})$ & $0.16^{\star \star \star}$ & $0.62^{\star \star \star}$ & $0.47^{\star \star *}$ & $0.06^{\star * *}$ & $-0.08^{\star \star \star}$ & -0.03 & 0.001 & 64.4 \\
\hline Fibre $(g)$ & $0.62^{\star \star \star}$ & 0.002 & $0.49^{\star \star \star}$ & 0.01 & $0.20^{\star \star \star}$ & 0.01 & $-0.19^{\star \star \star}$ & 69.2 \\
\hline Fat $(\mathrm{g})$ & $0.31^{\star \star \star}$ & $0.53^{\star \star \star}$ & $0.53^{\star \star \star}$ & $0.34^{\star \star *}$ & $-0.12^{\star \star \star}$ & $0.10^{\star \star \star}$ & $-0.05^{\star \star}$ & 79.3 \\
\hline $\begin{array}{l}\text { Saturated fatty } \\
\text { acids }(\mathrm{g})\end{array}$ & $0.22^{* * *}$ & $0.51^{\star \star \star}$ & $0.57^{\star \star \star}$ & $0.26^{\star \star \star}$ & $-0.18^{\star \star \star}$ & $0.10^{* * *}$ & $-0.05^{\star \star}$ & 74.6 \\
\hline$n-3$ fatty acids $(\mathrm{g})$ & $0.38^{* * *}$ & $0.39^{\star \star *}$ & $0.30^{* * *}$ & $0.34^{* * *}$ & $-0.08^{\star \star \star}$ & $0.05^{\star *}$ & $-0.10^{\star \star \star}$ & 52.0 \\
\hline Vitamin $D(\mu \mathrm{g})$ & $0.50^{\star \star \star}$ & $0.13^{\star \star *}$ & $0.19^{\star \star *}$ & $0.19^{\star \star \star}$ & $0.11^{\star \star \star}$ & $0.07^{\star \star \star}$ & -0.02 & 35.3 \\
\hline Vitamin E (mg) & $0.61^{\star \star \star}$ & $0.40^{\star \star \star}$ & $0.42^{\star \star \star}$ & $0.18^{\star \star \star}$ & 0.04 & $0.05^{\star \star}$ & $-0.08^{\star \star \star}$ & 74.6 \\
\hline Vitamin C (mg) & $0.47^{\star \star \star}$ & $0.30^{\star * *}$ & $0.09^{\star * *}$ & $0.05^{\star *}$ & -0.04 & $-0.05^{\star \star}$ & $-0.23^{\star \star \star}$ & 38.2 \\
\hline Carotenoids ( $\mu \mathrm{g}$ ) & $0.65^{\star \star \star}$ & 0.03 & $0.06^{\star \star *}$ & $0.10^{* * *}$ & $0.15^{\star \star \star}$ & 0.01 & $-0.09^{\star \star *}$ & 46.9 \\
\hline Folate (mg) & $0.67^{\star \star \star}$ & $0.21^{\star * *}$ & $0.44^{\star \star \star}$ & $0.18^{\star \star \star}$ & $0.09^{\star \star \star}$ & $0.07^{\star \star \star}$ & $-0.19^{\star \star \star}$ & 79.1 \\
\hline Iron $(\mathrm{mg})$ & $0.55^{\star \star \star}$ & $0.21^{\star \star *}$ & $0.54^{\star \star *}$ & $0.21^{\star \star \star}$ & $0.13^{\star \star \star}$ & $0.08^{\star \star \star}$ & $-0.13^{\star \star \star}$ & 71.6 \\
\hline Magnesium (mg) & $0.55^{\star \star \star}$ & $0.26^{\star \star \star}$ & $0.50^{\star \star *}$ & $0.13^{\star \star *}$ & $0.15^{\star \star \star}$ & $0.21^{\star \star \star}$ & $-0.20^{\star \star \star}$ & 74.4 \\
\hline Zinc (mg) & $0.50^{\star \star \star}$ & $0.21^{\star *}$ & $0.54^{\star \star \star}$ & $0.26^{\star \star \star}$ & $0.13^{\star \star \star}$ & $0.12^{\star *}$ & $-0.20^{\star \star \star}$ & 73.3 \\
\hline Calcium (mg) & $0.31^{\star \star \star}$ & $0.24^{\star * *}$ & $0.40^{\star \star *}$ & $0.08^{\star \star *}$ & $0.13^{\star \star \star}$ & $0.11^{\star \star \star}$ & $-0.23^{\star \star \star}$ & 39.9 \\
\hline Nitrate $(\mathrm{mg})$ & $0.80^{* * *}$ & -0.01 & $0.04^{\star *}$ & $0.13^{\star \star *}$ & $0.08^{\star \star *}$ & -0.04 & $0.06^{\star \star \star}$ & 67.0 \\
\hline Nitrite (mg) & $0.24^{\star \star \star}$ & $0.26^{\star \star *}$ & $0.34^{\star \star *}$ & $0.51^{\star \star \star}$ & $0.16^{\star \star \star}$ & $0.16^{\star \star *}$ & $-0.05^{\star \star}$ & 55.5 \\
\hline
\end{tabular}

${ }^{\star \star} P<0.01,{ }^{* \star *} P<0.001$; the strongest associations $(\geq 0.40$ and $\leq-0.40)$ are shown in bold.

tThe sum of squared correlations between absolute nutrient intake and pattern scores.

area and the number of earlier deliveries (Table 5). Positive associations were observed for age and the 'Healthy' and 'Alcohol and butter' patterns, while the 'Fast foods' and 'Traditional meat' patterns showed inverse associations. Positive associations were seen between educational level and the 'Healthy', 'Low-fat foods' and 'Alcohol and butter' patterns. Smoking during pregnancy was associated with 'Fast foods', 'Traditional meat' and with the 'Coffee' pattern, in particular. The number of earlier deliveries was positively associated with 'Traditional bread', 'Traditional meat' and 'Coffee' patterns, while inverse associations were observed for 'Fast foods' and 'Low-fat foods' patterns.

\section{Discussion}

We have identified and described seven dietary patterns among pregnant Finnish women. The patterns were differently related to energy and nutrient intakes and the sociodemographic factors of the women.

The extensive DIPP birth cohort with a high participation rate provided an excellent opportunity for examining the dietary patterns of pregnant Finnish women. The possible effects of the knowledge that the child carried increased HLA-conferred susceptibility to type 1 diabetes mellitus on maternal dietary habits should be considered. We collected information retrospectively concerning maternal diet during the eighth month of pregnancy, although diet during the early stages of pregnancy is perceived to be more important for foetal growth and development. However, earlier findings regarding maternal diet during pregnancy suggest that dietary patterns do not change significantly from preconception to 6 months postpartum $^{4}$. The FFQ used in this study was developed for the Nutrition Study within the DIPP. To effectively study the putative effects of maternal diet during pregnancy on the development of type 1 diabetes in the offspring, we needed a dietary instrument that could be administered after delivery when the genetic disease susceptibility of the offspring had already been determined. In the validation study by Erkkola et $a l^{16}$, the correlation coefficients between the second questionnaire, completed 1 month after delivery, and the food records were similar to those obtained between the first questionnaire, completed during the period of interest (eighth month of pregnancy), and the food records.

The influence of current diet is an important possible source of bias for the assessment of remote diet, and the diet during past pregnancy is recalled with perhaps slightly lower accuracy than adult diet generally ${ }^{18}$. However, in the study of Bunin et $a l^{18}$ the time gap between assessment and the period of interest was 3-7 years whereas it was only a few months in our study. Some recent investigations have reported reasonable validity for questionnaires concerning adolescent diet recalled by adults many years later ${ }^{19,20}$.

Dietary pattern analysis is used increasingly in nutritional research but it still has weaknesses. It is well known that factor analysis requires decisions to be made at several steps, starting with aggregation of dietary variables, the number of factors to be retained and 
concluding with naming the factors ${ }^{21}$. These decisions may affect the final results. Patterns are retained in an explorative way rather than established a priori, and are therefore unlikely to be reproducible in populations with different dietary habits ${ }^{5}$. On the other hand, Balder et $a l^{22}$ suggest that some important eating patterns may be shared by various populations.

Dietary patterns have not been reported previously in pregnant Finnish women. In three Finnish cohort studies among women and men ${ }^{22-24}$ two important dietary patterns emerged: healthy and traditional. The dietary data of these studies were collected in the $1960 \mathrm{~s}^{24}$ and the $1980 \mathrm{~s}^{22,23}$. Compared with our results of seven dietary patterns, it can be presumed that today there is more variation in peoples' eating habits than before. This is partly due to the wider selection of food products available and the presence of different eating styles, even during pregnancy.

According to our results it seems that age and education are positively correlated with 'Healthy' and 'Alcohol and butter' dietary patterns, whereas 'Fast foods' shows an inverse association. Earlier findings also revealed that healthy eating patterns are related to older age $e^{6,8,25,26}$ and higher educational level ${ }^{6,26}$ in women and men. However, in the study by Sánchez-Villegas et al. ${ }^{9}$, higher educational level among women was associated with greater adherence to a 'Western' dietary pattern (similarities with our 'Fast foods' pattern). Smoking was strongly associated with the 'Coffee' and 'Fast foods' dietary patterns. The consumption of coffee was highly correlated with smoking also in pregnant Mexican American women $^{3}$, although in that study coffee was omitted from the dietary pattern analysis. Furthermore, social, demographic and lifestyle factors related to the mother have been implicated to have an influence on the early eating patterns of the offspring ${ }^{2}$. It is suggested that food behaviour and concrete food choices are already established in childhood or adolescence and may track significantly into adulthood ${ }^{23}$. This emphasises the importance of identifying risk groups for targeted dietary guidance among mothers.

The seven dietary patterns identified provide a meaningful interpretation of the dietary data among pregnant Finnish women. Dietary patterns offer a framework for further research concerning diet and health outcomes among both mothers and their offspring. Next we will focus on the associations between dietary patterns and maternal weight gain during pregnancy.

\section{Acknowledgements}

Sources of funding: The DIPP Nutrition Study was supported by the Academy of Finland (grants 63672, 79685, 79686, 80846, 201988 and 210632), the Finnish Diabetes Association, the Finnish Diabetes Research 
Foundation, the Finnish Paediatric Research Foundation, the Juho Vainio Foundation, the Medical Research Fund of Tampere University Hospital, the Yrjo Jahnsson Foundation, and the Alma and KA Snellman Foundation. The DIPP Core Study was supported by Special Public Grants for Medical Research at the participating university hospitals, the Academy of Finland, the Juvenile Diabetes Research Foundation International (grants 197032 and 4-1998-274), the Novo Nordisk Foundation and EU Biomed 2 (BMH4-CT98-3314).

Conflict of interest declaration: None.

Authorship responsibilities: S.M.V. designed the Nutrition Study in DIPP and is responsible for the study. M.K. participated in the protocol development. S.M.V., T.A., U.U., R.V. and M.-L.O. were responsible for the present study concept and design. Statistical analysis was designed by M.V., T.A., S.M., M.G.K. and S.M.V., and performed by T.A. C.K.-K. was responsible for coordination of the field study and the data acquisition. U.U., C.K.-K., T.A. and S.M.V. were responsible for data processing and its supervision. The first draft of the manuscript was written by T.A. All authors contributed to the interpretation of the results and revising the manuscript.

Acknowledgements: We are grateful to all the mothers, study nurses and research scientists who took part in this study.

\section{References}

1 Jacques PF, Tucker K. Are dietary patterns useful for understanding the role of diet in chronic disease? American Journal of Clinical Nutrition 2001; 73: 1-2.

2 North K, Emmet P, The Avon Longitudinal Study of Pregnancy and Childhood (ALSPAC) Study Team. Multivariate analysis of diet among three-year-old children and associations with socio-demographic characteristics. European Journal of Clinical Nutrition 2000; 54: 73-80.

3 Wolff $\mathrm{CB}$, Wolff HK. Maternal eating patterns and birth weight of Mexican American infants. Nutrition and Health 1995; 10: 121-34.

4 Cucó G, Fernández-Ballart J, Sala J, Viladrich C, Iranzo R, Vila $\mathrm{J}$, et al. Dietary patterns and associated lifestyles in preconception, pregnancy and postpartum. European Journal of Clinical Nutrition 2006; 60: 364-71.

5 Schulze MB, Hoffmann K, Kroke A, Boeing H. Dietary patterns and their associations with food and nutrient intake in the European Prospective Investigation into Cancer and Nutrition (EPIC)-Potsdam study. British Journal of Nutrition 2001; 85: 363-73.

6 Williams DEM, Prevost AT, Whichelow MJ, Cox BD, Day NE, Wareham NJ. A cross-sectional study of dietary patterns with glucose intolerance and other features of the metabolic syndrome. British Journal of Nutrition 2000; 83: 257-66.

7 Mishra G, Ball K, Arbuckle J, Crawford D. Dietary patterns of Australian adults and their associations with socioeconomic status: results from the 1995 National Nutrition Survey. European Journal of Clinical Nutrition 2002; 56: 687-93.

8 Costacou T, Bamia C, Ferrari P, Riboli E, Trichopoulos D, Trichopoulou A. Tracing the Mediterranean diet through principal components and cluster analyses in the Greek population. European Journal of Clinical Nutrition 2003; 57: $1378-85$.

9 Sánchez-Villegas A, Delgado-Rodríguez M, Martínez-González MÁ, de Irala-Estévez J. Gender, age, socio-demographic and lifestyle factors associated with major dietary patterns in the Spanish Project SUN (Seguimiento Universidad de Navarra). European Journal of Clinical Nutrition 2003; 57: 285-92.

10 Robinson SM, Crozier SR, Borland SE, Hammond J, Barker DJP, Inskip HM. Impact of educational attainment on the quality of young women's diets. European Journal of Clinical Nutrition 2004; 58: 1174-80.

11 Haste FM, Brooke OG, Anderson HR, Bland JM, Shaw A, Griffin J, et al. Nutrient intakes during pregnancy: observations on the influence of smoking and social class. American Journal of Clinical Nutrition 1990; 51: 29-36.

12 Erkkola M, Karppinen M, Järvinen A, Knip M, Virtanen SM. Folate, vitamin D, and iron intakes are low among pregnant Finnish women. European Journal of Clinical Nutrition 1998; 52: 742-8.

13 Mathews F, Yudkin P, Smith RF, Neil A. Nutrient intakes during pregnancy: the influence of smoking status and age. Journal of Epidemiology and Community Health 2000; 54 : 17-23.

14 Bodnar LM, Siega-Riz AM. A diet quality index for pregnancy detects variation in diet and differences by sociodemographic factors. Public Health Nutrition 2002; 5: 801-9.

15 Arkkola T, Uusitalo U, Pietikäinen M, Metsälä J, KronbergKippilä C, Erkkola M, et al. Dietary intake and use of dietary supplements in relation to demographic variables among pregnant Finnish women. British Journal of Nutrition 2006; 96: 913-20.

16 Erkkola M, Karppinen M, Javanainen J, Räsänen L, Knip M, Virtanen SM. Validity and reproducibility of a food frequency questionnaire for pregnant Finnish women. American Journal of Epidemiology 2001; 154: 466-76.

17 KTL (National Public Health Institute, Finland). Food composition database Finel ${ }^{\mathbb{R}}$. Helsinki: KTL, 2005. Also available at http://www.fineli.fi.

18 Bunin GR, Gyllstrom ME, Brown JE, Kahn EB, Kushi LH. Recall of diet during a past pregnancy. American Journal of Epidemiology 2001; 154: 1136-42.

19 Maruti SS, Feskanich D, Colditz GA, Frazier AL, Sampson LA, Michels KB, et al. Adult recall of adolescent diet: reproducibility and comparison with maternal reporting. American Journal of Epidemiology 2005; 161: 89-97.

20 Maruti SS, Feskanich D, Rockett HR, Colditz GA, Sampson LA, Willett WC. Validation of adolescent diet recalled by adults. Epidemiology 2006; 17: 226-9.

21 Martinez ME, Marshall JR, Sechrest L. Invited commentary: Factor analysis and the search for objectivity. American Journal of Epidemiology 1998; 148: 17-19.

22 Balder HF, Virtanen M, Brants HAM, Krogh V, Dixon LB, Tan F, et al. Common and country-specific dietary patterns in four European cohort studies. Journal of Nutrition 2003; 133: 4246-51.

23 Mikkilä V, Räsänen L, Raitakari OT, Pietinen P, Viikari J. Consistent dietary patterns identified from childhood to adulthood: The Cardiovascular Risk in Young Finns Study. British Journal of Nutrition 2005; 93: 923-31.

24 Montonen J, Knekt P, Härkänen T, Järvinen R, Heliövaara M, Aromaa A, et al. Dietary patterns and the incidence of type 2 diabetes. American Journal of Epidemiology 2005; 161: 219-27.

25 Slattery ML, Boucher KM, Caan BJ, Potter JD, Ma K-N. Eating patterns and risk of colon cancer. American Journal of Epidemiology 1998; 148: 4-21.

26 Terry P, Hu FB, Hansen H, Wolk A. Prospective study of major dietary patterns and colorectal cancer risk in women. American Journal of Epidemiology 2001; 154: 1143-9. 